\section{A novel method for closure of a choledocho- duodenostomy in sump syndrome}

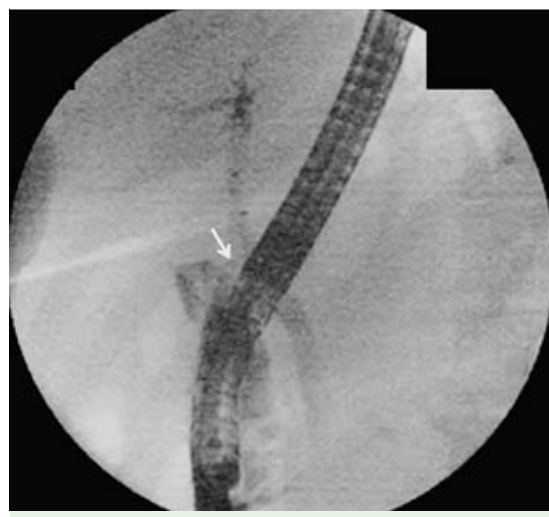

Fig. 1 Fluoroscopic image showing drainage of the contrast dye via the choledochoduodenostomy anastomosis (arrow).

A 57-year-old woman with a history of a complicated open cholecystectomy and side-to-side choledochoduodenostomy (CDD) 25 years previously was admitted to our hospital with cholangitis. She had undergone five endoscopic retrograde cholangiopancreatography (ERCP) procedures with stone and debris extractions in another hospital during the preceding 2 years.
ERCP revealed a patent biliary sphincterotomy and CDD orifice that was proximal to the papilla of Vater. Injection of contrast showed that dye drained via the CDD anastomosis ( $\bullet$ Fig. 1). Several small pieces of debris were extracted using a balloon-tipped catheter (Eliminator Biliary Balloon Dilators; ConMed, Utica, New York, USA), and an 8-cm long, fully covered self-expanding metal stent(SEMS; WallFlex; Boston Scientific, Natick, Massachusetts, USA) was placed through the papilla of Vater

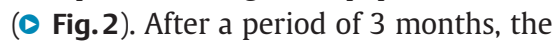
fully covered SEMS was retrieved uneventfully, and complete closure of the CDD orifice was observed during the ERCP procedure ( $\bullet$ Fig. 3 a). A repeat injection of contrast confirmed the closure of the CDD orifice with no evidence of any drainage of the contrast dye ( $\bullet$ Fig. $\mathbf{3}$ b).

Limited data exist regarding endoscopic closure of CDDs in sump syndrome. Ell et al. [1] used an amplatzer septal occluder for successful CDD closure; however, this technique seems to be difficult and may not be available in many endoscopy centers. Recently, Ellison et al. [2] used an over-the-scope clip; however, the success rate of this method depends on the diameter of the CDD orifice. In addition, we believe that this method could result in formation of a biliary stricture. The new method presented, using a fully covered SEMS, is technically easy, safe, and effective for closure of a CDD in sump syndrome. We suggest that a minimum stent indwell time of 3 months is needed for successful closure of a CDD.

Endoscopy_UCTN_Code_TTT_1AR_2AG

\section{Competing interests: None}

\section{Galip Ersoz, Fatih Tekin, Ilker Turan, Oktay Tekesin, Omer Ozutemiz}

Department of Gastroenterology, Ege

University Medical School, Izmir, Turkey

\section{References}

1 Ell C, Boosfeld C, Henrich R et al. Endoscopic treatment of the "sump syndrome" after choledochoduodenostomy: a new technique using an amplatzer septal occluder. $\mathrm{Z}$ Gastroenterol 2006; 44: 1231 -1235

2 Ellison JC, Tarnasky PR. Endoscopic management of sump syndrome: closure of choledochoduodenostomy. Gastrointest Endosc 2014; 80: 725-726
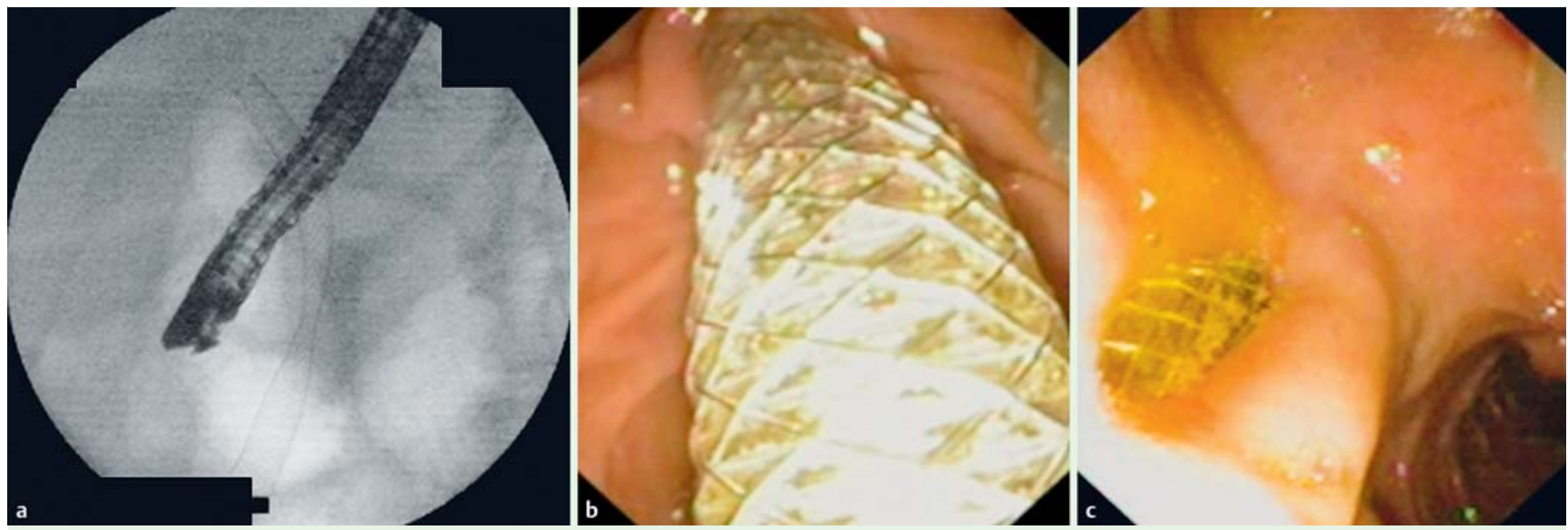

Fig. 2 The fully covered self-expanding metal stent seen on: a fluoroscopic view; $\mathbf{b}$ endoscopic view showing it passing through the papilla of Vater; $\mathbf{c}$ endoscopic view through the choledochoduodenostomy anastomosis. 


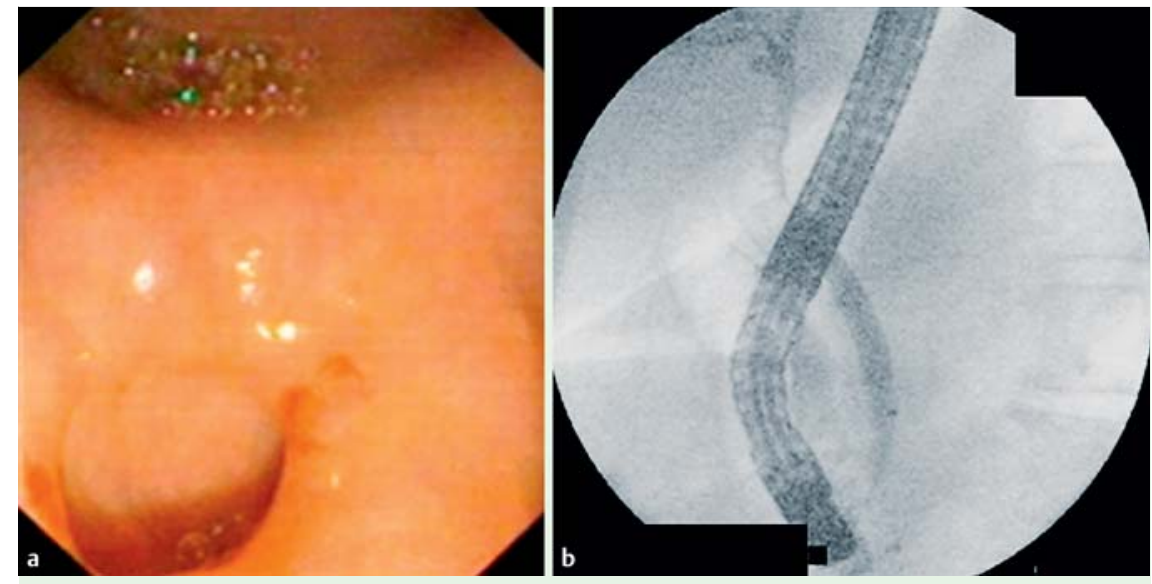

Fig. 3 a Endoscopic view 3 months later after retrieval of the self-expanding metal stent showing complete closure of the choledochoduodenostomy orifice. $\mathbf{b}$ Fluoroscopic image during endoscopic retrograde cholangiopancreatography (ERCP) 3 months later showing no evidence of drainage after injection of contrast dye, confirming the complete closure of the choledochoduodenostomy.

\section{Bibliography}

Dol http://dx.doi.org/

10.1055/s-0034-1392504

Endoscopy 2015; 47: E365-E366

(c) Georg Thieme Verlag KG

Stuttgart · New York

ISSN 0013-726X

\section{Corresponding author}

\section{Fatih Tekin, MD}

Ege Universitesi Tip Fakultesi

Gastroenteroloji Bilim Dali

Bornova 35100

Izmir

Turkey

Fax: +90-232-3427764

drtekinfatih@gmail.com 